\title{
Insight into an Acquired Accent of Maritime English Learners
}

\author{
Olena Tyron \\ State University of Infrastructure and Technologies, Kyiv, Ukraine \\ Email: ollena22@hotmail.com
}

How to cite this paper: Tyron, O. (2018). Insight into an Acquired Accent of Maritime English Learners. Psychology, 9, 897-910. https://doi.org/10.4236/psych.2018.95055

Received: April 2, 2018

Accepted: May 6, 2018

Published: May 9, 2018

Copyright $\odot 2018$ by author and Scientific Research Publishing Inc. This work is licensed under the Creative Commons Attribution International License (CC BY 4.0).

http://creativecommons.org/licenses/by/4.0/

\begin{abstract}
The target audience of this article is Maritime English teachers. We have been researching students' pronunciation before and after a shipboard training in multinational crews. We described the phenomena: The students after a long (approximately 6 months' shipboard training at sea) returned in the English lecture room with a new acquired accent. From the planed interviews with the surveyed we got information about the national composition of the multinational crews. Then we analyzed information about the peculiar properties of these nations' pronunciation. We also studied the features that form an accent in English of the Ukrainians. We claim that the theory of converge (make their speech similar to the style of their addressee) and diverge (make their speech different to the style of their addressee) can explain the accent of the students after the shipboard training in a multinational crew. But we assert that inaccuracies in the pronunciation of certain words can distort the accuracy of the utterance and will lead to violations of professional activity. In this connection we consider that any accent in seafarers' speech has a negative effect on the safety of navigation and seafarers should tend to Standard English pronunciation. Nevertheless, an acquired accent as a result of convergent behavior, have a positive effect in the social-psychological aspect. The research proves that the teachers of Maritime English should: consider the accent as manifestation of ability to use convergence; teach and accept only Standard English especially in the context of safety of navigation; understand the psychological origins of the desire to demonstrate the acquired accent as a manifestation of divergence and skillfully shape the motivation of students to have a standard pronunciation.
\end{abstract}

\section{Keywords}

Maritime English Teaching, Acquired Accent, Convergent and Divergent Behavior, Multinational Crew 


\section{Introduction}

For a year we have been researching students' pronunciation before and after a shipboard training in multinational crews. We noticed such phenomena: The students after a long (approximately 6 months' shipboard training at sea) returned in the English lecture room with a newly acquired accent. The Maritime English teachers even could guess the national composition of the crew where the students had had a voyage. We also noticed that mostly those students didn't make any attempts to adjust the vocalic features of their speech to Standard English pronunciation. This situation aroused the following questions which English language teachers had to answer:

1) Is a new accent which students acquired during activity in the multinational crew a cultural, social, psychological or linguistic problem?

2) What is the theoretical background of the speech adjustment?

3) Are the accents of crucial importance for the activity of future seafarers?

4) Should the L2 English teachers prevent the pronunciation shifting among the students after the shipboard training in the multinational crew?

5) What are the differences and similarities between teachers' and students' attitudes regarding pronunciation in a foreign language (L2)?

6) What motivates the students to shift speech and/or to have Standard English pronunciation?

Understanding of an accent in L1 and L2 acquisition is different. Macmillan English Dictionary defines the term accent "a way of saying words that shows what country, region or, social class someone comes from"

(http://www.macmillandictionary.com). For a foreign accent, there is not an exact and comprehensive definition which is universally accepted. However, the general consensus is that the term covers the defects in the pronunciation of non-native speech compared to the norms of native speech (Gut, 2009). Thus, the non-native teacher with a foreign accent can be claimed to possess deviations in articulation, rhythm, voice, and symbolization (Hansen \& Arslan, 1995).

We should mention that speaking about accents we do not mean regional deviation from the generally accepted standards. In L2 teaching by the accent we understand deviations caused by the influence of the phonetic structure of the native language, the familiar physiological characteristics of the movement of the speech apparatus in the native language, insufficient level of teaching, and individual abilities to learn foreign languages. For our research, we used pronunciation patterns given in Oxford English Dictionary on line (http://public.oed) and other sites with the relevant information (https://en.wikipedia.org), etc.

\section{Vocalic Environment of the Seafarers in Multicultural Crews}

Nowadays, ship-owners tend to form international crews, the accepted fact which is explained by economic factor. The composition of international crews was studied by some scientists and it was found out that there are 7 main nations 
which constitute the main portion of nautical professionals. They are the Philippines, Chinese, Indians, Turks, Ukrainians, Russians and Indonesians. Therefore, we were researching accents within the frame of these nations (Erol, Lane, \& Sampson, 2001). According to the requirements of International Maritime Organization and other documents which state the requirements to the seafarers' training English language is compulsory for international marine communication (Maritime English (2015). ModelCourse 3.17). Schematically, the model of the global distribution of the English language can be represented in the form of three concentric circles. The first, inner circle includes “old" English-speaking countries, in which English was the first, dominant language-Britain, the United States, Canada, Australia and New Zealand. The representatives of these countries are native speakers of English. Of course, they also have regional accents but generally, tend to use Standard English. The portion of these nations is not high in international crews and the students, who get in the environment of native speakers during their shipboard training, return to the classroom with the much-improved level of English. These students improve fluency, acquire "right" accent which is acceptable even when they get some shift of Standard (e.g. very open æx and $\mathrm{r}$ in the words of the third type of syllable). The teachers immediately guess that the student was sailing in the American crew.

The countries of the second circle include India, Nigeria, Pakistan, Singapore, South Africa, the Philippines and Zambia, and many others (this list includes forty countries in all). The countries of the second circle belong to densely populated territories, thus significantly increasing the number of English-speaking people in the world. These countries have English as the second national language. It means that English is widely used for wide variety of purposes, such as education or social and political life.

Countries belonging to the third, outer circle include China, Indonesia, Iran, Japan, Korea, and Nepal, etc. In these countries, English has many destinations, widely studied for narrower purposes than in the countries of the second circle. It is likely that the process of globalization will make it possible to rank by the third circle practically all countries of Western and Eastern Europe. A high portion of seafarers in international crews belongs to this circle: Chines, Ukrainians, Turks, Russians and Indonesians.

Here we are giving some extracts which depict the features of pronunciation which:

- The similar to the Ukrainian language;

- Prevent the adequate perception of speech on the level of words.

\section{Ukrainians}

The most obvious features of the pronunciation in the Ukrainian language are the absence of short and long vowels. Ukrainians tend to lessen long vowels. The sound /g/ mostly pronounced as /h/ by Ukrainians. The absence of sounds $/ \theta /$, $/ ð /, / \partial /$ and some others lead to the most striking challenges in mastering English pronunciation. The British and American English sounds $/ \theta /$ and $/ ð /$ are often pronounced as /s/ and /z/ by Ukrainians. Syllable-final /b/, /d/, /g/, /v/, /ð/, /z/, 
$/ 3 /$ and $/ \mathrm{d}_{3} /$ may be often pronounced as their voiceless counterparts $(/ \mathrm{p} /, / \mathrm{t} /$, $/ \mathrm{k} /, / \mathrm{f} /, / \theta /, / \mathrm{s} /, / \mathrm{J} /$ and $/ \mathrm{t} \mathrm{J} /$, respectively). The physiological basis for the production of speech sounds - the difference in the place of the tongue even if the sound is similar to Ukrainian sounds. The influence of the specifics of the pronunciation of the native language is manifested precisely when the spontaneous speech in a foreign language. When the speech is within the studied topic, the teacher predicts the content of the speech and the pronunciation of the student doesn't influence the understanding. The spontaneous speech is understood as it heard. When we hear / $\sin /$ instead of / $\theta \mathrm{in} /$, we wonder what "sin" the speaker is talking about. This may become the problem for understanding in inter-ship communication. And misunderstandings in such communication may cause threats to safe navigation.

\section{Philippine English}

The dictionary says that in Philippine English, words which would have /3/ in British or American Englishes (e.g. leisure) have / $/$ / instead, while the British and American English sounds $/ \theta /$ and $/ \partial /$ are Philippine English $/ \mathrm{t} /$ and $/ \mathrm{d} /$ respectively. Philippine English is similar to U.S. English in retaining $/ \mathrm{r} /$ after vowels wherever it occurs, e.g. mar/mar/, unlike British /ma:/.

\section{Hong Kong English}

The additional symbol /o/ is used in Hong Kong English to indicate a "vocalized" /l/ at the ends of words such as able /'erbo/. Words with /v/ in British or American Englishes are pronounced with either /w/ or /f/ in Hong Kong English, while words which would have /z/ or / $3 /$ in British or American Englishes have voiceless /s/ and $/ \mathrm{J} /$ respectively. Where $/ \theta /$ occurs in British English it is /f/ in Hong Kong English, but /ð/ becomes /d/ (e.g. thing/fin/, though/dov/) except in word-final position where it is / $t /$. In Hong Kong English there is no distinction between $/ \mathrm{p} /$ and $/ \mathrm{b} /, / \mathrm{t} /$ and $/ \mathrm{d} /$, or $/ \mathrm{k} /$ and $/ \mathrm{g} /$ word-finally, so they are respectively transcribed as $/ \mathrm{p} /, / \mathrm{t} /$, and $/ \mathrm{k} /$ in this position.

\section{Indonesians}

Very rhotic/r/ sound (more rhotic than the American one). Indonesians, like many non-native English speakers, have difficulty in pronouncing /th/ sound. Simple words like "the", "this", and "that" will sound like "de", "dis", and "dat". $/ \mathrm{ch} /$ and /sh/ sounds are often simplified to /c/ and /s/ sounds. A tendency to lengthen short vowel into the long vowel. For many Indonesians, "hit" and "heat" are homophones. Indonesians have a problem with silent letters. They tend to pronounce all letters.

All these differences may cause some social-psychological problems in interpersonal communication (socializing) but if referred to the maritime industry (navigation, bunkering, pilotage, mooring, radio communication, search and rescue operations and other professional activities on the ship) misunderstandings in communication may lead to disastrous consequences. Another aspect of variety between languages of different cultures is the speed and rhythm of an utterance. Tone and pitch are other nuances of the language that are acquired during the language acquisition process. The volume of voice is one more speech 
component which differs depending on the nation. For example, South East Asia crews use a lower volume in their speech, while some European Mediterranean and Arab countries may raise their voices when emphasizing certain points in their messages, or when talking to someone at some distance. Thus, an Asian crew can perceive someone from a loud volume culture to be angry, while the lower volume Asians may be perceived as timid and non-assertive. Moreover, giving orders by raising the voice can make the crew lose face, thus creating a tense atmosphere on boardships (Badawi, 2002). Cross-cultural education with some emphases on pronunciation peculiarities in English (L2) will play an important role in promoting better communication for the marine multinational crews belonging to different cultures.

\section{Theory}

Here we describe scientific theories and notions we use in our research. The leading place is given to speech accommodation theory (later widen to communication accommodation theory). Howard Giles developed the core concepts of speech accommodation theory in the 1970s (Giles, 1973; Giles \& Powesland, 1975, Giles \& Coupland, 1991) and this approach was developed and further renamed as communication accommodation theory. Practical application of this approach for professional purposes is depicted in the work by Marianne Dainton, Elaine D. Zelley (2014). Accommodation theory draws on four social-psychological theories in order to explain style shifts: 1) the theory of similarity attraction; 2) social-exchange theory (greatest reward and smaller cost); 3) the theory of casual attribution (evaluate one another's behavior according to their interpretation of the motives); 4) intergroup distinctiveness (attempt to maintain the group identity) (Jenkins, 2005).

Rod Ellis (1994) calls Speech Accommodation theory a social-psychological model of language use. Speakers can converge (make their speech similar to the style of their addressee) or diverge (make their speech different to the style of their addressee). Speech accommodation is motivated by the attitudes of speakers hold towards their audience (Ellis, 1994).

Goals of speech accommodation may be defined as: evoke listeners' social approval; attain communication efficiency; maintain positive social identities (Beebe, 1987). Later, speech accommodation theory was widened with ethnolinguistic-identity theory and intergroup theory. John H. Esling (1994) also studied the varieties of voice and connected it with speakers' social identity. He noted that "speakers vary in the voice quality settings of their accents accordingly to the social dialect they speak". The researcher stresses that "sociolinguistically distinct groups maintain their regional or social identities by means of the long-term, habitual, articulatory postures of accent that are described as voice quality settings".

Transmitting utterances, speakers convey information using not only acoustic means but also paralinguistic ones. "Human speech is the main vehicle by which 
verbal and linguistic communication is transmitted. But spoken communication also carries other messages that are nonverbal in nature. Vocal qualities such as pitch, rhythm, tempo, resonance, control, and accent lend meaning to the spoken word. The study of these nonverbal elements of the voice is called vocalics, or paralinguistics (Anderson, 1998: p. 69). It is known that some accents sound more attractive than others. This value of judgment affects how people perceive each other's accent and drives them to form stereotypical associations that frequently describe people's perceptions of foreign accent as abnormal and flawed (Giles \& Coupland, 1991).

\section{Experimental Materials and Methods}

We present here an empirical research which has been carried out at the State University of Infrastructure and Technologies, Institute of Water Transport (Ukraine). On the basis of theoretical positions, we have developed a methodology and identified methods of experimental psycholinguistic research. 30 students (future seafarers-navigators) and 20 teachers of English for Professional purposes participated in the research. The subject of our study is an accent in English language of seafarers. The methods we used: observing, individual interviews and a questionnaire with the aims: 1) to get information about communication environment in multinational crews; 2) to diagnose the students and teachers' attitude to the role of pronunciation.

After the first stage of the research (individual interviews) we obtained such information:

1) General information about the shipboard training of the surveyed, namely: vessel's port of registry, type of vessel, voyage duration. The answers were distributed in the following way: A half of students underwent shipboard training under a foreign flag and a half-under a national flag.

2) Information about the structure of crew: Number of crew members, national structure, nationality of the ship-owner, nationality of officers, nationality of the lower ranks. We found out that students had shipboard training on vessels with the international crew mostly with Filipinos, Chinese, Turks, Russians, Hindus, Indonesians, Bulgarians, Germans, Italians, British and Americans.

3) Data on life conditions on the vessel (the fatigue, threat of piracy attacks and other factors described in the first section).

All interviewed confirmed existence of the specified features of life activity on the vessel. Surveyed who had experience of shipboard training in zones of the threat of piracy attacks described their psychological experiences, feelings of high danger to life (4.5\% of surveyed endured attempts of piracy attack, $8.1 \%$ catastrophic threats which led to casualties).

The students confirmed the influence of such social-psychological factors as emotional pressure, the monotony period, physical inactivity, an accurate work-rest schedule, the ratio of sleeping hours and wakefulness, deficiency of information, restriction of a stream of irritants of the natural and social envi- 
ronment; the nature of intergroup relationship, long stay in the isolated environment, unity and compatibility of crew; loneliness and so forth.

4) Students were asked if they felt a difference in behavior of the Asian and European seamen. All students who had experience of life activity in the international crews confirmed the difference in behavior of the Asian and European seamen. They were all struck by divergences in behavior, the culture of consumption of food, gestures, the way of speaking and popular topics for socializing.

5) Some students noted that the general psychological climate on the vessel was not always positive. There were conflict situations between officers and inferior personnel that sometimes led to the determination of the certain seaman and even replacement of the captain of the vessel.

6) We asked if the students were getting pleasure from communication with crew members, and 27\% gave the answer "yes", and 73\% noted that they just fulfilled the professional duties, and "on communication, there was no time".

After these interviews we got full information about:

- Communication environment in multinational crews;

- Features of life activity the students will have while having a shipboard training at sea;

- Social and psychological problems the students may have while having a shipboard training in a multinational crew.

The second stage of the research was the testing. The students were asked to give the answers to the questioner "Attitudes to the role of pronunciation in L2." The students answered on the scale: Completely agree - quite agree - don't know quite disagree - completely disagree. Bellow, there are questions of the test.

1) Having a good pronunciation reflects my level of English proficiency.

2) Poor pronunciation in English prevents effective work during an international voyage.

3) Strong accent prevents effective communication between members of the international crew.

4) I can determine which country is a person from by their accent in English.

5) Strong accent in English gives the impression that a person is poorly educated.

6) A good pronunciation informs of such features of a person's character as persistence, diligence, and the ability to organize their time.

7) Good pronunciation will contribute to my career growth.

8) Your English accent is shaped by the influence of your native language.

9) Your pronunciation in English is influenced by your teacher's pronunciation.

10) Trying to sound like a native speaker, you lose your national identity.

The aims of the questioner "Attitudes to the role of pronunciation in L2": 1) define student's ability to estimate the role of pronunciational abilities in their professional and interpersonal communication; 3) define whether a national language is a physiological and psychological barrier in mastering pronunciation 
in L2; 3) define the influence of teacher's pronunciation and teaching process. Here are the numbers of questions which show: 1 ) influence of good pronunciation in professional life: 2,$7 ; 2$ ) influence of good pronunciation in interpersonal communication: $3,4,5,6 ; 3)$ influence of national language on pronunciation: 8 , $10 ; 4)$ influence of teaching on pronunciation: $1,9$.

In Table 1, you see the summary of the students' answers. We interpreted the answers of 30 surveyed in such way: completely agree + quite agree $=$ high role of accuracy in pronunciation in regards of Standard English; quite disagree + completely disagree $=$ low role of accuracy in pronunciation in regards of Standard English; no opinion = students couldn't answer due to different reasons (never analyzed pronunciation, not sure they understand the question, etc.)

The $66 \%$ of surveyed agree that pronunciation influences their professional activity, demonstrate awareness of the danger of misunderstandings for navigation, inter-ship communication, and other professional operations. The $78 \%$ of surveyed agree that their native language influence much their pronunciation in the English language. It means Maritime English teachers should pay attention to the comparative phonology, correct student's pronunciation taking into account physiological features and differences in vocalic apparatus of Ukrainians and native speakers of English. Only 30\% of surveyed accept the influence of pronunciation in interpersonal communication. A low percentage of respondents who recognize the role of pronunciation for interpersonal communication show the orientation of students to professional activities. But it is in interpersonal communication that students are easily influenced by the interlocutor's accent and adjust their pronunciation to the interlocutor's speech. The results show the need to correct the teacher's approach to teaching standard pronunciation when they should show the possibilities and dangers of adjusting the pronunciation. The $35 \%$ of respondents accept the influence of teaching quality on pronunciation. The result confirms that modern technologies have entered the learning process of a foreign language and students don't rely only on a teacher and widely use the possibilities of the Internet, video and audio programs, manuals for self-study. Wide access to various sources of information limited the role of the teacher as a standard of the foreign language and students realize this. There have passed the times when foreign language learners in all their failures, including pronunciation problems, blamed the teacher.

Table 1. Results of the students' questionnaire "Attitudes to the roles of pronunciation in L2" (\%).

\begin{tabular}{ccccc}
\hline Levels & $\begin{array}{c}\text { professional } \\
\text { communication }\end{array}$ & $\begin{array}{c}\text { interpersonal } \\
\text { communication }\end{array}$ & $\begin{array}{c}\text { influence of national } \\
\text { language }\end{array}$ & $\begin{array}{c}\text { influence of } \\
\text { teaching }\end{array}$ \\
\hline High role & 66 & 30 & 78 & 35 \\
Low role & 20 & 29 & 11 & 35 \\
No opinion & 14 & 41 & 11 & 30 \\
\hline
\end{tabular}


Thus, the questionnaire shows that more English language teachers' attention should be paid to the correction of students' attitude to the role of pronunciation in inter-personal communication.

We also asked 10 teachers of Maritime English to answer the same questions as the students did. Our aim was to find out if the teachers and their students "act in the same direction", do not have contradictions in their attitudes to the role of pronunciation. We note that the teachers are non-native teachers of English. By non-native teachers are usually understood the teachers for whom the language they teach is not their mother tongue. They work with the learners whose mother tongue is usually the same as that of students'. Some non-native teachers deliberately carry a strong foreign accent in their speech to announce their national identity. For this reason, their English is far from being accurate, fluent, and sounds non-natural to the students (Demirezen, 2007). Further, Medgyes (1992) reports that these teachers feel insecure and unconfident using the language they have to teach and they might suffer from Foreign Accent Syndrome (FAS), referring to a fear of speaking in the field of language education.

The information how non-native teachers of English who teach future seafarers answered the questions about their attitude to the role of pronunciation is given in Table 2.

The $75 \%$ of teachers agree that pronunciation will influence the professional activity of future seafarers. It is stated in the educational programs approved by the educational institution according to the requirements of IMO (International Maritime Organization). The fact that $25 \%$ of surveyed accept that pronunciation will not influence the future seafarers' professional activity much puzzled us but it can be explained by the lack of teaching experience of some teachers. Almost all teachers (92\%) agree that students' native language influence much pronunciation in the English language. It means L2 English teachers should pay attention to the comparative phonology, correct student's pronunciation taking into account physiological features and differences in vocalic apparatus of Ukrainians and native speakers of English. Thus, attentive students can put the teacher in a difficult situation with negative reactions to their foreign accent. To avoid all of these, the non-native teachers should correct their foreign accents and sound more near native-like. Half of surveyed teachers (46\%) accept the influence of pronunciation in interpersonal communication. Some English teachers yield the opinion of individual foreign language learners who argue that pronunciation is not so important for interpersonal communication, the main

Table 2. Results of the English teachers' questionnaire "Attitudes to the roles of pronunciation in L2" (\%).

\begin{tabular}{ccccc}
\hline Levels & professional activity & $\begin{array}{c}\text { interpersonal } \\
\text { communication }\end{array}$ & $\begin{array}{c}\text { influence of national } \\
\text { language }\end{array}$ & $\begin{array}{c}\text { influence of } \\
\text { teaching }\end{array}$ \\
\hline High role & 75 & 46 & 92 & 50 \\
Low role & 25 & 40 & 8 & 25 \\
No opinion & - & 14 & - & 25 \\
\hline
\end{tabular}


thing is to convey information. This fact allows to assume that such teachers are not aware of the existence of the Theory of Speech Accommodation, convergence, and divergence, therefore theoretical knowledge of the teacher requires correction. The $50 \%$ of teachers agree that teaching and teachers play the main role in pronunciation forming. In our opinion, they just overestimate their role in this process. In the past, teachers were the only source of knowledge in the lecture room but the situation changed due to modern technologies.

In order to find out if the teachers and their students do not have contradictions in their attitudes to the role of pronunciation, we compared the percentage of the answers which confirm the high level of influence in each option. The result you can see in Table 3.

As you can see in Table 3, the students and the teachers treat the role of pronunciation in the same way. We observe that the teachers demonstrate higher results which can be explained by their professional background as linguists.

On the second stage of our research we used the questioner "Attitudes to the role of pronunciation in L2". The results proved that correction is needed to form student's ability to estimate the role of pronunciational abilities in interpersonal communication; a national language is a physiological and psychological barrier in mastering pronunciation in L2; the influence of teacher's pronunciation and teaching process is overestimated by the non-native teachers.

\section{Discussion}

The theory of converge (make their speech similar to the style of their addressee) and diverge (make their speech different to the style of their addressee) can explain the accent of the students after the shipboard training in a multinational crew. Communicating with the Philippines, Indonesians, Indians they converge, trying to sound the same way, to demonstrate that they belong to their group. But having returned to the lecture room they want to demonstrate that they were sailing under the foreign flag. It is prestigious to have shipboard practice on a foreign ship. Not all students can get the post of a cadet on such ship. To get it students study hard, have several interviews in crewing companies and undergo severe selection. Students, who couldn't overcome successfully such selection, have shipboard training on the national ships in inland waters. So, the students demonstrate that they are "different", they diverge trying to attract teachers and other students' attention to the fact of working in multinational crews by using specific accent.

Table 3. Difference in students' and teachers' attitudes.

\begin{tabular}{ccccc}
\hline High Levels & $\begin{array}{c}\text { professional } \\
\text { communication }\end{array}$ & $\begin{array}{c}\text { interpersonal } \\
\text { communication }\end{array}$ & $\begin{array}{c}\text { influence of national } \\
\text { language }\end{array}$ & $\begin{array}{c}\text { influence of } \\
\text { teaching }\end{array}$ \\
\hline student & 66 & 30 & 78 & 35 \\
teachers & 75 & 46 & 92 & 50 \\
difference & +9 & +16 & +14 & +15 \\
\hline
\end{tabular}


Inaccuracies in the pronunciation of certain words can distort the accuracy of the utterance. Listeners perceive words as they should be pronounced in Standard English, they may not know the specifics of national accents, may not know the speaker's nationality, thus frustrating the perception of the message, which will lead to violations of professional activity. In this connection we consider that the acquired accent of the students as a result of convergent behavior have a negative effect on the safety of navigation. Nevertheless it may have a slight positive effect in the social-psychological aspect. The students quickly find friends for communication, show their belonging to the already formed group of sailors, receiving its support, thus protecting themselves from loneliness and other psychological interpersonal problems.

The research is made for the teachers of Maritime English and as a result of this research we think that they should:

- consider the accent as the manifestation of ability to use convergence;

- teach and accept only Standard English especially in the context of the safety of navigation;

- understand the psychological origins of the desire to demonstrate the acquired accent as a manifestation of divergence and skillfully shape the motivation of students to have a standard pronunciation.

\section{Practical Recommendations to the Maritime English Teachers}

1) Make the students aware of possibilities of convergence and divergence. As a result of this awareness your students will understand:

- in what way to make your interlocutor perceive you positively taking advantage of the similarity of speech;

According to the communication-accommodation theory (Street, 1982; Street \& Brady, 1982; Street \& Giles, 1982), listeners perceive speech similar to their own as more attractive, pleasant, and intelligible. Moreover, speakers typically adjust or accommodate their speech to the style or rate of the other interactant, even though most speakers are unaware of this accommodation (Street, 1982).

- how to show your competence and power;

Research by Berry $(1990,1992)$ demonstrates that people with more attractive voices were judged to be more warm, likable, honest, dominant, and achieved oriented. She found that people with less mature, babyish vocal qualities were perceived as less powerful and less competent but warmer and more honest than people with mature-sounding voices.

- how to maximize your credibility;

Ketrow, S.M. (1990) concludes that to maximize one's credibility and social attractiveness, a person should speak fluently and slightly faster than one's listeners and use a moderately loud voice, a standard dialect, and clear diction.

There are many other tricks which can be taught to students in the regards of Speech Accommodation Theory. 
2) Motivate the students to use Standard English pronunciation. Attract students' attention that:

- good pronunciation contributes to career growth;

- good pronunciation has a status;

- mistakes in pronunciation may lead to misunderstanding;

- misunderstandings may lead to inevitable consequences.

3) Use different exercises that form phonetic competence of L2 learners. The example of such exercise you can see below.

Random sounds (procedure)

1) Ask the learners to close their eyes, perhaps even to rest their head on their arms. Invite them to listen carefully to every sound they can heat, and to try to identify the sounds. They should be listening for all the "natural" noises of the classroom, the building and outside.

2) Let everyone listen for two or three minutes and then write down what they heard.

3) Then ask them about what they heard. Games are taken from the book of games by Wright, A., Betteridge, D., \&Buckby, M. (2006).

\section{Conclusions}

Shipboard training of future seafarers in multinational crew evokes specific vocalic environment which may result in "acquired accent". This accent doesn't have constant character and it can be explained on the basis of Speech Communication theory. The students of the maritime branch while communicating during their shipboard training with the crew members of certain nationalities adjust their speech (converge) and after the voyage indirectly demonstrate their involvement in international navigation, demonstrate their status as a "successful seafarer" to the group-mates and the teachers (diverge).

This process takes place on a subconscious level, the "acquired accent" is not stable, with the skillful application of psychological and pedagogical techniques is easily eliminated. We tend to call this accent "false" or "fake". Thus, a new accent which students acquire in the process of activity in the multinational crew has a cultural, social, psychological and linguistic background.

Maritime English teachers' attention should be paid to the correction of students' attitude to the role of pronunciation in inter-personal communication and motivate their students to use Standard English pronunciation.

The results of the research proved that psychological correction is needed to form student's ability to estimate the role of pronunciational abilities in interpersonal communication; a national language is a physiological and psychological barrier in mastering pronunciation in L2; the influence of teacher's pronunciation and teaching process is overestimated by the non-native teachers.

Maritime English teachers should pay attention to the comparative phonology, correct student's pronunciation taking into account physiological features and differences in vocalic apparatus of Ukrainians and native speakers of Eng- 
lish, should correct their foreign accents and sound more near native-like.

\section{References}

Anderson, P. A. (1998). Nonverbal Communication: Forms and Functions. USA: Mayfield Publishing Company.

Badawi, E. (2002). The Implication of Cross Culture Communication on Ship's Crew. Alexandria: AAST\&Mt.

Beebe, L. M. (1987). Speech Accommodation Theory. In L. M. Beebe (Ed.), Issues in Second Language Acquisition: Multiple Perspectives. USA: Heinler \& Heinler Publishers.

Berry, D. S. (1990). Vocal Attractiveness and Vocal Babyishness: Effects on Stranger, Self and Friend Impressions. Journal of Nonverbal Behavior, 14, 141-153. https://doi.org/10.1007/BF00996223

Berry, D. S. (1992). Vocal Types and Stereotypes: Joint Effects of Vocal Attractiveness and Vocal Maturity on Person Perception. Journal of Nonverbal Behavior, 16, 41-54. https://doi.org/10.1007/BF00986878

Dainton, M., \& Zelley, E. D. (2014). Applying Communication Theory for Professional Life: A Practical Introduction. Sage Publications.

Demirezen, M. (2007). Identity Problems of Non-Native Teachers of English in Teacher Education. The Internet TESL Journal, 8 . http://iteslj.org/Articles/Demirezen-NonNativeTeachers.html

Ellis, R. (1994). The Study of Second Language Acquisition. Oxford, UK: Oxford University Press.

Erol, K., Lane, T., \& Sampson, H. (2001). Transnational Seafarer Communities. London: Cardiff University.

Esling, J. H. (1994) Some Perspectives on Accent: Range of Voice Quality Variation, the Periphery and Focusing/Pronunciation Pedagogy and Theory: New Views, New Directions.

Giles, H. (1973). Accent Mobility: A Model and Some Data. Anthropological Linguistics, 15, 87-105.

Giles, H., \& Coupland, N. (1991). Language: Contexts and Consequences. Keynes: Open University Press.

Giles, H., \& Powesland, P. F. (1975). Speech Style and Social Evaluation. Oxford: Academic Press.

Gut, U. (2009). Non-Native Speech. A Corpus-Based Analysis of Phonological and Phonetic Properties of L2 English and German. Frankfurt am Main: Peter Lang. https://doi.org/10.3726/978-3-653-01155-5

Hansen, J. H. L., \& Arslan, L. M. (1995). Foreign Accent Classifications Using Source Generator Based Prosodic Features. In International Conference on Acoustics, Speech, and Signal Processing (Vol. 1, pp. 836-839). Piscataway, NJ: IEEE. https://doi.org/10.1109/ICASSP.1995.479824

Jenkins, J. (2005). Implementing an International Approach to English Pronunciation: The Role of Teacher Attitudes and Identity. TESOL Quarterly, 39, 535-543. https://doi.org/10.2307/3588493

Ketrow, S. M. (1990). Attributes of a Telemarketer's Voice and Persuasiveness: A Review and Synthesis of the Literature. Journal of Direct Marketing, 4, 7-21. https://doi.org/10.1002/dir.4000040304 
Maritime English (2015). Model Course 3.17. London: IMO. http://www.imo.org

Medgyes, P. (1992). Native or Non-Native: Who's Worth More? ELT Journal, 46, 340-349. https://doi.org/10.1093/elt/46.4.340

Street, R. L. (1982). Evaluation of Noncontent Speech Accommodation. Language and Communication, 2, 13-31. https://doi.org/10.1016/0271-5309(82)90032-5

Street, R. L., \& Brady, R. M. (1982). Speech Rate Acceptance Ranges as a Function of Evaluative Domain, Listener Speech Rate and Communication Context. Communication Monographs, 49, 290-308. https://doi.org/10.1080/03637758209376091

Street, R. L., \& Giles, H. (1982). Speech Accommodation Theory: A Social Cognitive Approach to Language and Speech Behaviour. In M. Roloff, \& C. Berger (Eds.), Social Cognition and Communication (pp. 193-226). Beverly Hills, CA: Sage.

Wright, A., Betteridge, D., \& Buckby, M. (2006). Games for Language Learning (3rd ed.). Cambridge: Cambridge University Press. 